\title{
Pulmonary kinetic expression of the endothelin system in a swine model of endotoxic shock
}

\author{
A. Zannoni • C. Bernardini • F. Gentilini • M. Giunti • \\ M. L. Bacci - M. Forni
}

Published online: 2 May 2010

(C) Springer Science+Business Media B.V. 2010

\begin{abstract}
Endothelin(ET)-1 is a potent vasoconstrictor peptide involved in the derangement of respiratory mechanics during endotoxic shock. We measured the kinetics of pulmonary mRNA expression of the key components of the ET system [i.e., ET-1, ET-converting enzyme (ECE), and ETA and ETB receptors] by quantitative real-time reverse transcriptase-polymerase chain reaction in a swine model of endotoxic shock $(0,1,2,3$, and $4 \mathrm{~h}$ of continuous LPS infusion at $40 \mu \mathrm{g} / \mathrm{kg}$ /hour; sham group, 4 hour saline infusion). A significant increase in mRNA expression levels was observed for ET-1 in LPS-treated piglets; the increase began as early as 1 hour. In contrast, no significant variations were observed for the ECE, ETA, or ETB genes. Small gene expression differences observed with respect to our previous results suggest a possible effect of the anesthesia or surgical protocol on ET system regulation.
\end{abstract}

Keywords Endothelin $\cdot$ LPS $\cdot$ Lung $\cdot$ Shock $\cdot$ Swine

\author{
Abbreviations \\ ET-1 endothelin 1 \\ ECE-1 endothelin-1 converting enzyme \\ ETA endothelin A \\ ETB endothelin B \\ LPS lipopolysaccharide
}

\section{Introduction}

Endotoxic shock is a pathological condition associated with cardiac dysfunction, pulmonary hypertension, systemic hypotension, and altered mechanical properties of the

\footnotetext{
A. Zannoni $(\bowtie) \cdot$ C. Bernardini $\cdot$ M. L. Bacci $\cdot$ M. Forni Veterinary Medicine Faculty, Department of Veterinary Morphophisiology and Animal Production (DIMORFIPA), University of Bologna, Bologna, Italy

e-mail: augusta.zannoni@unibo.it

F. Gentilini $\cdot$ M. Giunti

Veterinary Medicine Faculty, Department of Veterinary Clinic (DCV), University of Bologna, Bologna, Italy
} 
respiratory system. Endothelin (ET)-1 is a potent vasoconstrictor peptide involved in the dysfunction of respiratory mechanics during endotoxic shock (Ohta et al. 1990). The peptide is primarily synthesized by a broad variety of cells, and the lung is the major site of both clearance and production of circulating ET-1 (Dupuis et al. 1996). ET-1 is synthesized as a prepropeptide molecule and is converted into an active peptide by endothelin-1 converting enzyme (ECE-1). ET-1 effects are mediated by at least two receptors, $\mathrm{ET}_{\mathrm{A}}$ and $\mathrm{ET}_{\mathrm{B}}$, and their blockade abolishes pulmonary hypertension and worsens systemic hypotension induced by lipopolysaccharide (LPS) (Ciminaghi et al. 2003). The roles of the ET system's key components (ET-1, ECE-1, $\mathrm{ET}_{\mathrm{A}}$, and $\mathrm{ET}_{\mathrm{B}}$ ) in sepsis are not yet fully clarified. Our previous study in a porcine model (Forni et al. 2005) showed that an LPS infusion (lasting $4 \mathrm{~h}$ ) induced opposite effects on the various components of the ET-1 system in the lung: an increase of ET-1 mRNA and a decrease in the mRNA levels of the other components. Since ET-1 peptide has a short half-life (15-20 min) (Galiè et al. 2004), the aim of the present research was to evaluate lung ET system expression levels at different times after LPS treatment during porcine endotoxic shock.

\section{Material and methods}

Experiments were performed in accordance with local, national, and European laws for the care and use of laboratory animals. Twelve large, white piglets of both sexes, weighing $13.0 \pm$ $2.43 \mathrm{~kg}$ (mean $\pm \mathrm{SE}$ ) and about 2 months old, were sedated with medetomidine hydrochloride (Domitor, $10 \mathrm{~mL}$ Pfizer, $25 \mu \mathrm{g} / \mathrm{Kg}$ i.m.), tiletamine $\mathrm{HCl}$, and Zolazepam $\mathrm{HCl}$ (Zoletil 100, Virbac, $5 \mathrm{~kg}$ i.m.) and anesthetized with a bolus of $15 \mathrm{mg} / \mathrm{kg}$ thiopental sodium (Pentothal Sodium, Intervet, $15 \mathrm{mg} / \mathrm{kg}$ i.v.) injected into the auricular vein. Anesthesia was maintained by continuous infusion of thiopental sodium $(9 \mathrm{mg} / \mathrm{kg} / \mathrm{h})$. The animals were orotracheally intubated and mechanically ventilated using a Siare Falcon 201/B ventilator with medical air (setting 15-20 breaths/min). Pigs were randomly assigned to receive $0,1,2,3$, and $4 \mathrm{~h}$ (T0, T1, T2, T3, and T4; $n=10$ ) i.v. infusion of $40 \mu \mathrm{g} / \mathrm{kg} / \mathrm{h}$ Escherichia coli LPS (serotype 055:B5, Sigma, diluted in $0.9 \%$ sterile saline solution) or saline solution only for $4 \mathrm{~h}$ (sham group, $n=$ 2). Animals were then euthanized ( $6 \mathrm{~mL}$ Tanax ${ }^{\circledR}$ i.v., embutramide, mebenzonium iodide, and tetracaine hydrochloride), and lung samples were taken for RNA extraction. Real-time quantitative PCR was performed using an iCycler thermocycler (Bio-Rad). Specific porcine primers for ET-1, ECE-1, ET $\mathrm{A}_{\mathrm{A}}, \mathrm{ET}_{\mathrm{B}}$, and hypoxanthine phosphoribosyltransferase (HPRT, housekeeping gene) were designed, and real-time PCR (SYBR green I) was performed as previously described (Forni et al. 2005). Relative gene expression levels were calculated using the $2^{-\Delta \Delta C T}$ method (Applied Biosystems User Bulletin \#2, 2001) relative to the control T0. Statistical significances of differences were determined using the one-way analysis of variance (ANOVA; $p<0.05$ was considered significant).

\section{Results}

The gene expression levels of ET-1, ECE-1, ET $\mathrm{A}$, and $\mathrm{ET}_{\mathrm{B}}$ in the lung are shown in Fig. 1. Our results showed that LPS treatment induced a gradual increase, as early as $1 \mathrm{~h}$, of ET-1 mRNA, reaching a maximum value after $4 \mathrm{~h}$ of LPS (12-fold increase with respect to control T0). ET-1 gene expression in the sham group did not change, showing that our surgical protocol did not influence gene expression levels. LPS treatment did not significantly influence ECE-1 gene expression; in the sham group, there was a slight increase in ECE-1 levels that was higher than 

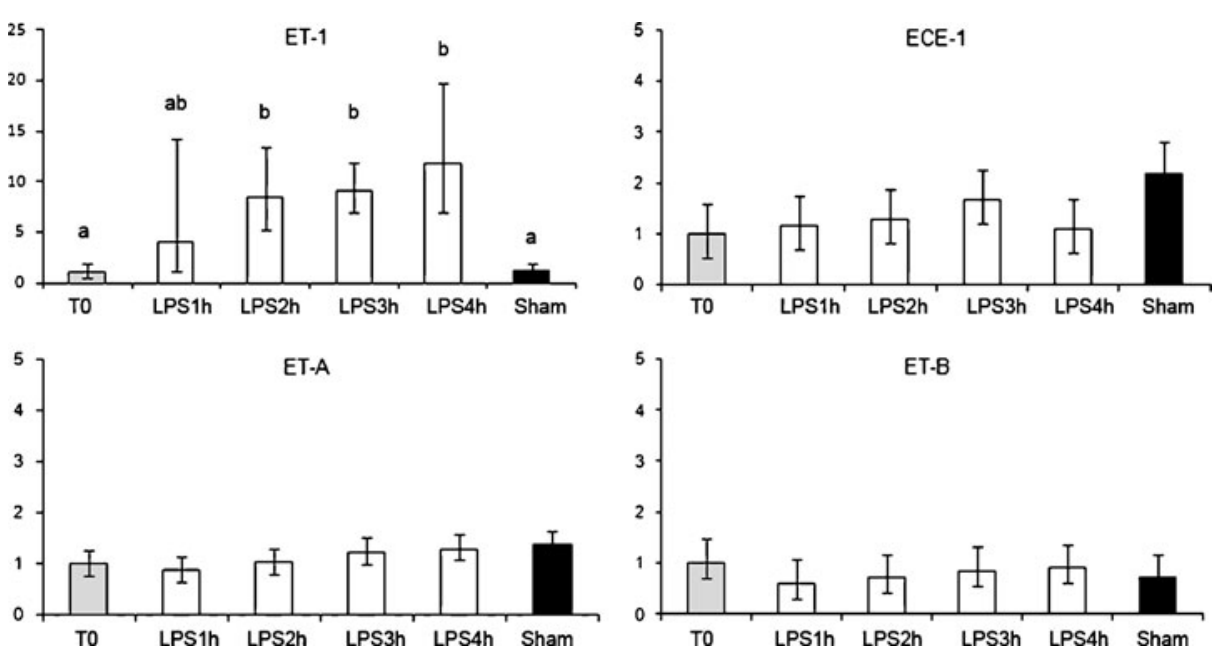

Fig. 1 Relative gene expression of ET-1, ECE-1, $\mathrm{ET}_{\mathrm{A}}$, and $\mathrm{ET}_{\mathrm{B}}$ in lungs of piglets after infusion with either LPS $(1,2,3$, and $4 \mathrm{~h}$ ) or saline solution (sham $4 \mathrm{~h}$ ). Gene expression levels were calculated as the fold increase relative to control (T0). Different letters indicate statistically significant differences $(p<0.05$; ANOVA, Duncan's test)

with LPS treatment but this increase was not statistically significant. The gene expression levels of the receptors did not significantly change even with a slight increase in the levels of $\mathrm{ET}_{\mathrm{A}}$ and a slight decrease in the levels of $\mathrm{ET}_{\mathrm{B}}$ in both the treated and sham groups.

\section{Discussion}

This study provides evidence that the surgical protocol utilized did not influence the gene expression levels of key components of the ET-1 system in the lung. LPS treatment was able to induce an increase in ET-1 gene expression in the lung. The increase began after $1 \mathrm{~h}$ of treatment and continued for $4 \mathrm{~h}$, confirming that LPS is a strong stimulus for ET-1 mRNA induction. In contrast, LPS did not influence the gene expression levels of ECE-1, $\mathrm{ET}_{\mathrm{A}}$, or $\mathrm{ET}_{\mathrm{B}}$, in contrast to our previous results (Forni et al. 2005) in which LPS treatment at $4 \mathrm{~h}$ decreased their expression levels. These conflicting results suggest, together with the trends observed in the sham group, a possible effect of the anesthesiological/surgical protocol. Since assisted ventilation itself may influence pulmonary function to initiate or improve local and/or systemic inflammatory responses (Behnia et al. 1996; Uhlig 2002), it could also be responsible for the small differences in the expression levels of some ET system components observed during our studies.

Acknowledgements This research was supported by grants from PRIN, RFO 2007, and CITO.

\section{References}

Applied Biosystems (2001) User Bulletin \#2

Behnia R et al (1996) Early markers of ventilator-induced lung injury in rats. Ann Clin Lab Sci 26:437-450 
Ciminaghi B et al (2003) Endothelin-1 (ET-1) involvement in respiratory dysfunctions during endotoxic shock in pig. Vet Res Commun 27(Suppl. 1):221-224

Dupuis J et al (1996) Human pulmonary circulation is an important site for both clearance and production of endothelin-1. Circulation 94:1578-1584

Forni M et al (2005) Expression of endothelin-1 system in a pig model of endotoxic shock. Regul Pept 131:89-96

Galiè N et al (2004) The endothelin system in pulmonary arterial hypertension. Cardiovasc Res 61:227-237

Ohta K et al (1990) Cytokine-induced release of endothelin-1 from porcine renal epithelial cell line. Biochem Biophys Res Commun 169:579-584

Uhlig S (2002) Ventilation-induced lung injury and mechanotransduction: Stretching it too far? Am J Physiol Lung Cell Mol Physiol 282:892-896 